\title{
Simulation of Sudanese Sugar Cane Bagasse Gasification Process Using Aspen Plus
}

Mawa Mutaz Tagelsir, Hamid M. Mustafa \& Ibrahim H. Mohamed

Article history:

Received July 27, 2021

Received in revised form September 11, 2021

Accepted September 22, 2021

Available online October 13, 2021

( NRv) Journal of Karary University for Engineering and Science (JKUES)

Online ISSN: $1858-8000$

Print ISSN: 1858-800X

Journal
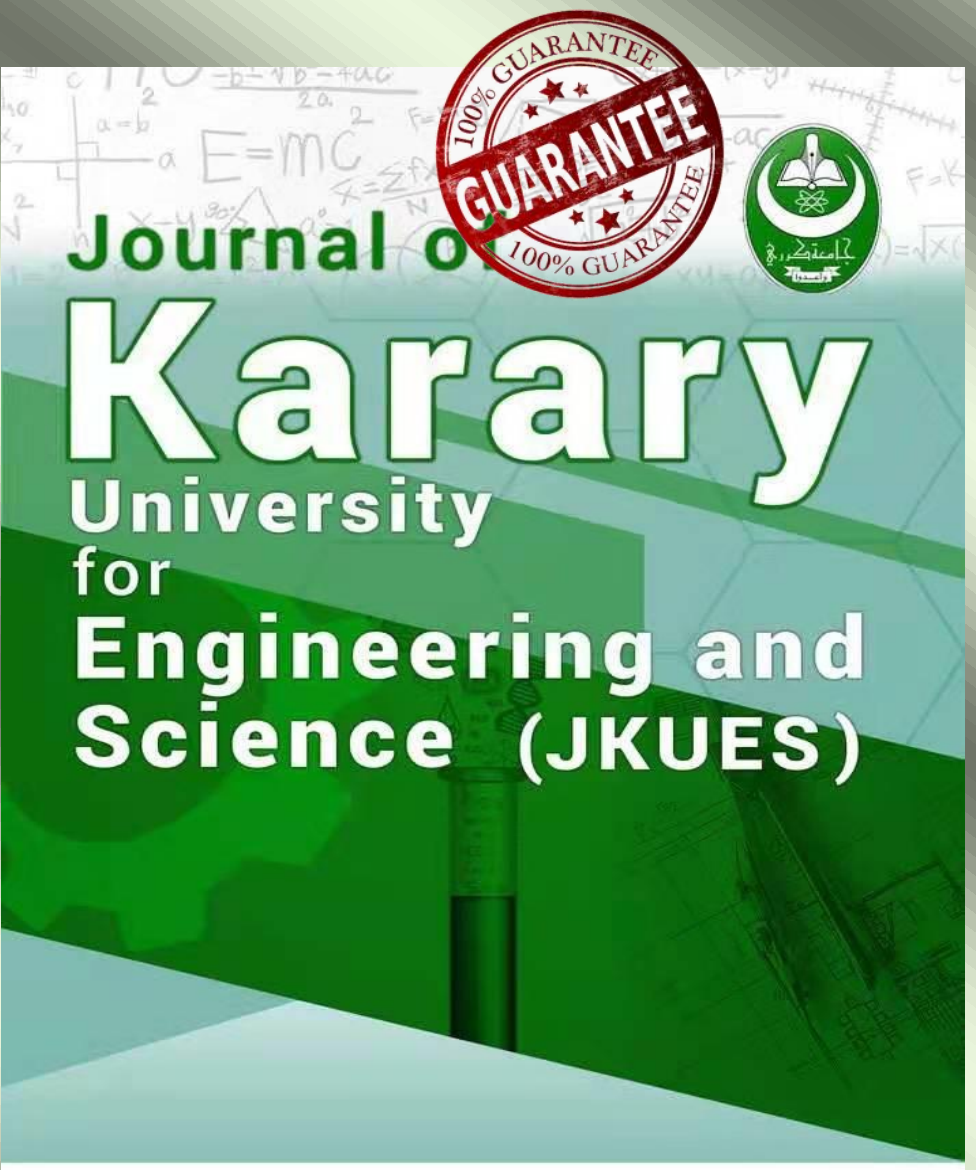

Online ISSN: 1858-8000

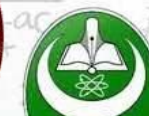

(2, 2 i.eli?

for

Engineering and Science (JKUES) 


\title{
Simulation of Sudanese Sugar Cane Bagasse Gasification Process Using Aspen Plus
}

\author{
Mawa Mutaz Tagelsir*,Hamid M. Mustafa ${ }^{\dagger}$, Ibrahim H. Mohamed ${ }^{\dagger}$ \\ *Karary University, Khartoum, Sudan, mawamutaz@gmail.com \\ $\dagger$ University of Science and Technology
}

\begin{abstract}
Bagasse has traditionally inefficiently burned in boilers for steam and electricity generation which still suffers from significant inefficiencies creating; therefore there is a need for alternative processes to be analyzed. Among the biomass utilization technologies, biomass gasification is an attractive solution for utilizing biomass effectively. In this study Aspen Plus simulation package V8 was used to develop a model for the gasification of Sudanese sugar cane bagasse in a fluidized bed reactor for syngas production. The developed model is based on Gibbs free energy minimization applying the non-stoichiometric equilibrium method for optimization of the gasifier performance. The objective is to study the effect of important operating parameters including gasification temperature, steam to biomass ratio (SBR) and air to biomass ratio (ABR), on syngas composition, low heating value (LHV) of syngas and cold gas efficiency (CGE). The optimal values of syngas composition, LHV and CGE were located at gasification temperature range from $750^{\circ} \mathrm{C}$ to $950^{\circ} \mathrm{C}$, steam to biomass ratio around 0.5 to 0.8 and air to biomass ratio values equal to or below 0.4 .
\end{abstract}

Key words-Biomass Gasification; Simulation Model; Synthesis Gas

\section{INTRODUCTION}

Rapid industrial progress has caused sudden increase of energy consumption. This phenomenon is especially visible in developing countries. Traditional methods of energy production were based on fossil fuels (mostly oil and gas), which caused consequences in form of excess emission of greenhouse gasses [14]. It is widely believed that there are strong linkages between fossil energy utilization and global environmental problems such as global warming. Cellulosic energy crops such as sugar cane biomass are one alternative to fossil fuel combustion for power generation and are part of a larger bioenergy strategy for coping with mitigation of greenhouse gases (GHG) emissions. Biomass can be processed by means of: thermo-chemical methods to liquid fuels, gasses (carbon oxides methane), or pyrolysis where hydrogen is the final product [9].

Gasification is a technological process that can convert any carbonaceous (carbon-based) raw material into fuel gas, also known as synthesis gas (syngas for short). It occurs in a gasifier, generally a high temperature/pressure vessel where oxygen (or air) and steam are directly contacted with the feed material causing a series of chemical reactions to convert the feed to syngas and ash/slag (mineral residues) [1].

Biomass gasification means incomplete combustion of biomass resulting in production of combustible gases consisting of Carbon monoxide (CO), Hydrogen $\left(\mathrm{H}_{2}\right)$ and traces of Methane $\left(\mathrm{CH}_{4}\right)$. This mixture is called producer gas. Producer gas can be used to run internal combustion engines (both compression and spark ignition), which can be used as substitute for furnace oil in direct heat applications and can be used to produce, in an economically viable way, methanol an extremely attractive chemical which is useful both as fuel for heat engines as well as chemical feedstock for industries [11].

\section{Statement of the Problem}

Agricultural wastes, and more generally biomasses, represent an attractive potential feedstock for sustainable energy production, having the advantage of low cost, easy access and greenhouse neutrality. Among biomasses, sugar cane residues (bagasse and so-called cane trash), due to their abundance in Sudan, can be an important alternative for the replacement of fossil fuel or at least an addition to energy sources. The current technologies together with those in development for conversion of cellulosic biomass into energy have the potential to contribute to the world energy needs and alleviate the impact of increasing $\mathrm{CO} 2$ emissions. In Sudan the use of bagasse as energy source doesnâĂŹt accomplishing the full potential due to the fact of combusting it directly, regardless of its precious energy value. Modernly, technological replacement of combustion process by gasification for the commercial production in the years to come can be a transformational change in the Sudanese sugar cane industry. The aim of this study is to maximize the beneficial yield of bagasse as a source of an alternative energy by developing a model that represents bagasse gasification process for working towards sustainable development of sugar cane industry. The effect of important operating parameters including gasification temperature, steam to biomass ratio (SBR) and air to biomass ratio (ABR), on syngas composition, low heating value (LHV) of syngas and cold gas efficiency (CGE) were investigated and the optimal values identified.

\section{Methodology}

\section{A. Simulation Model}

Aspen Plus simulation program was used to simulate the gasification phenomena. This simulation software was selected because it has the capability to define non-conventional fuels in terms of their ultimate and proximate analysis and has an extensive built in physical properties database which can be 
used in all simulation calculations[3]. Models that do not solve particular processes and chemical reactions in the gasifier and instead consist of overall mass and heat balances for the entire gasifier are called equilibrium models. Equilibrium models are generally based on chemical reaction equilibrium and take into account the second law of thermodynamics for the entire gasification process [10]. There are two general approaches for equilibrium modeling; one may use stoichiometric or nonstoichiometric methods. The mathematical model used in the stoichiometric method includes a set of chemical reactions for which the equilibrium constants are defined [6]. Because biomass gasification involves a series of complex reactions, the stoichiometric model are not suitable for this situation as every reaction should be considered in this model. The nonstoichiometric method is frequently used when simulating gasification process using Aspen Plus [12]. Contrarily, in the non-stoichiometric method, there is no need of knowing the reaction mechanism to resolve the problem. The equilibrium condition is attained by minimization of Gibbs free energy. This approach is termed non-stoichiometric due to the absence of any specific chemical reaction, other than the assumed global gasification reaction. Therefore, there is only one input required, the elemental composition, obtainable by ultimate analysis. For this reason, non-stoichiometric models are particularly suitable for cases in which all the possible reactions that can occur in the system are not fully known as is the case of gasification.

In this study, the developed Aspen Plus model involves the following steps: specification of stream class, selection of property method, determination of the system component from databank, specification of the conventional and nonconventional components, Specifying the process flow sheet by using unit operation blocks and connecting material and energy streams, defining feed streams (flow rate, composition, and thermodynamic condition) and Specifying unit operation blocks (thermodynamic condition, chemical reactions, etc.).

\section{B. Assumptions}

According to the features of Aspen Plus and the thermodynamic equilibrium model used for this simulation, the following assumptions were taken into account in simulation:

1) Gasification process is isothermal and operates under steady state conditions and zero dimensional.

2) Ash is inert and does not participate in chemical reactions.

3) Tar and heavy hydrocarbons are products of nonequilibrium reactions and thus are not considered in the model.

4) Particle size is not considered.

5) Pressure drops and heat loss for the reactors are neglected.

6) All reactions are reached equilibrium conditions and reaction kinetics is not taken into account.

7) All elements that compose the biomass. Yields into volatile products mainly consist of $\mathrm{H}_{2}, \mathrm{CO}, \mathrm{CO}_{2}, \mathrm{CH}_{4}$ and $\mathrm{H}_{2} \mathrm{O}$ beside char, $\mathrm{O}_{2}, \mathrm{~N}_{2}, \mathrm{Cl}_{2}$ and $\mathrm{S}$.

A global reaction of solid fuel gasification by oxygen can be written as [7]:

$$
\begin{aligned}
& \mathrm{CH}_{x} \mathrm{O}_{y} \mathrm{~N}_{z} \mathrm{~S}_{r}+s\left(\mathrm{O}_{2}\right) \longrightarrow x_{1} \mathrm{H}_{2}+x_{2} \mathrm{CO}_{2}+x_{3} \mathrm{CO}_{2}+ \\
& x_{4} \mathrm{H}_{2} \mathrm{O}+x_{5} \mathrm{CH}_{4}+x_{6} \mathrm{CH}_{x^{\prime}} \mathrm{O}_{y^{\prime}} \mathrm{N}_{z^{\prime}} \mathrm{S}_{r^{\prime}}+u \mathrm{H}_{2} \mathrm{~S}+x_{7} \mathrm{NH}_{3}
\end{aligned}
$$

where $\mathrm{x}, \mathrm{y}, \mathrm{z}$, and $\mathrm{r}$ represent the number of atoms of hydrogen, oxygen, nitrogen, and sulfur based on a single atom of carbon in the solid fuel, $\mathrm{s}$ represents moles of oxygen used per moles of solid fuel, $x_{1}, x_{2}, x_{3}, x_{4}, x_{5}, x_{6}$, and $x_{7}$ are the stoichiometric coefficients of each corresponding product. $x^{\prime}, y^{\prime}, z^{\prime}$, and $r^{\prime}$ show the number of atoms of hydrogen, oxygen, nitrogen, and sulfur based on a single atom of carbon in $\operatorname{tar}[7]$.

Syngas yield in this model is the volume of total product gas from the gasification per unit weight of fuel in normal conditions $\left(\mathrm{Nm}^{3} / \mathrm{kg}\right.$ of biomass). The lower heating value of product gas is calculated as [8]:

$$
\begin{aligned}
& L H V_{\text {syngas }}\left(\frac{K_{J}}{N m^{2}}\right)=4.2 \times \\
& \left(30 \times y_{c o}+25.7 \times y_{h_{2}}+85.4 \times y_{C_{4}}\right)
\end{aligned}
$$

Gasification efficiency or cold gas efficiency (CGE) is an important index to account for the performance of biomass gasification. It is defined as [4]:

$$
\begin{aligned}
& \text { GasificationEfficiency }= \\
& \frac{L H V_{\text {gas }}\left(\frac{M_{j}}{m^{2}}\right) \times \text { Volume }_{\text {gas }}\left(\frac{m 2}{h}\right)}{L H V_{\text {biomass }}\left(\frac{M j}{K g}\right) \times m_{\text {biomass }}\left(\frac{K g}{h}\right)}
\end{aligned}
$$

The LHV of biomass is $19.09(\mathrm{Mj} / \mathrm{kg})$ [12].

\section{Physical Property Method}

The PR-BM property method was selected as the global property method for this model. This method uses the Peng Robinson cubic equation of state with the Boston-Mathias alpha function (PR-BM) for all the thermodynamic properties, which is suitable for the nonpolar or mildly polar mixtures such as hydrocarbons and light gases. The parameter alpha in this property package is a temperature dependent variable that could be helpful for the correlation of the pure component vapor pressure when temperature is quite high. The PR-BM property method is recommended for the gas processing, refinery, and petrochemical applications [13]. Nonconventional solids in Aspen Plus do not participate in phase and chemical equilibrium calculations. They are characterized only by enthalpy and density models. HCOALGEN was selected as the enthalpy model for both biomass and ash. Different empirical correlations for heat of combustion, heat of formation and heat capacity are included in the HCOALGEN model. The density model was DCOALIGT which is based on equations from IGT (Institute of Gas Technology) [7], [13]. 


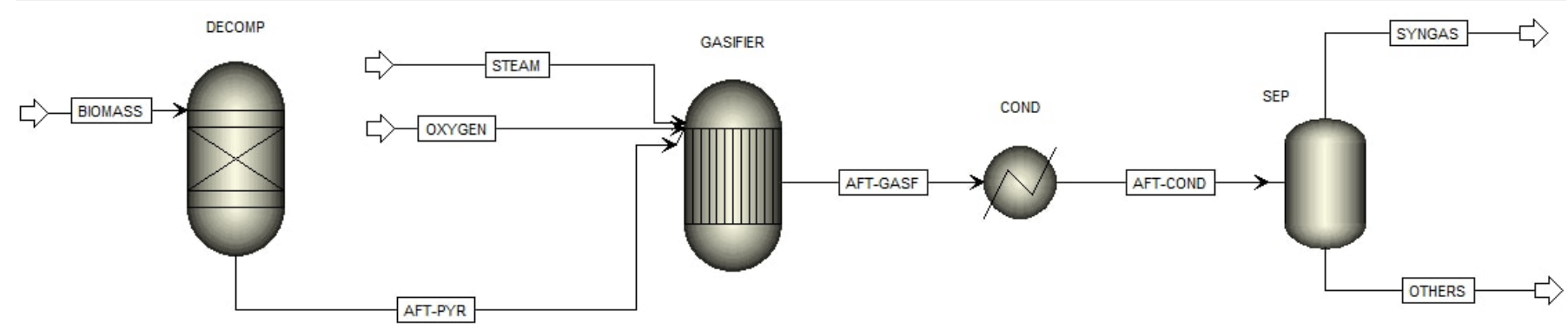

Fig. 1. Simulation flow sheet of Bagasse Gasification.

\section{Model Description}

In Aspen Plus, there is no particular gasifier model ready for use; therefore, it is necessary to split the whole process into different blocks that can be simulated with the existing models provided by Aspen Plus. The reactions occurring during the gasification process are presented in Table I. The flow-sheet of the simulation process is shown in Fig. 1. Dry bagasse is fed as a non-conventional component into a decomposition reactor (DECOMP) which converts the biomass into conventional components(C, H, O, N, S, and ASH). This is done by the RYield model with calculations that are based on the component yield specifications. A calculator block with a FORTRAN statement is used to specify the yield distribution according to the ultimate and proximate analysis of bagasse as considered in Table II and determines the mass flow rate of each component in the blocks outlet stream. The outlet stream from the block DECOMP is fed to the gasification reactor (GASIFIER) in the presence of steam and oxygen as gasification agents. The selected products were: $\mathrm{H}_{2}, \mathrm{CO}, \mathrm{CO}_{2}, \mathrm{CH}_{4}, \mathrm{H}_{2} \mathrm{~S}$, $\mathrm{SO}_{2}, \mathrm{HCl}, \mathrm{NH}_{3}$ and $\mathrm{H}_{2} \mathrm{O}$. The gasifier was modelled based on the minimization of Gibbs free energy model. Therefore, the RGIBBS reactor provided in Aspen Plus was chosen as a gasifier in order to simulate the gasfier as an adiabatic reactor the heat of reaction associated with bagasse decomposition was considered into the gasification step as shown by the heat stream Q-1. The gasification reactor outlet enters a condenser (COND) to cool down temperature of produced gas to lower temperature. The produced gases then pass through a flash block (SEP) to simulate the removal of water from the product.

Essential data concerning the dry bagasse constituent analysis carried out by Elbager [5], who used thermo-gravimetric analyzer. Elbager insured that dry bagasse from Sudan Sugar Factories contained the following components as shown in Table II. The Table III gives the brief descriptions of the unit operations of the blocks used in the simulation.

\section{REsults And Discussion}

The sensitivity analysis was performed with the aim to investigate and optimize the overall process conditions of bagasse gasification. In this simulation, gasification temperature was varied from $650^{\circ} \mathrm{C}$ to $1100^{\circ} \mathrm{C}$, steam to biomass ratio was varied from 0.2 to 1.0 and air to biomass ratio was varied from 0.1 to 0.8 . The composition of the produced gas; the lower heating value and the gasification efficiency were analyzed.

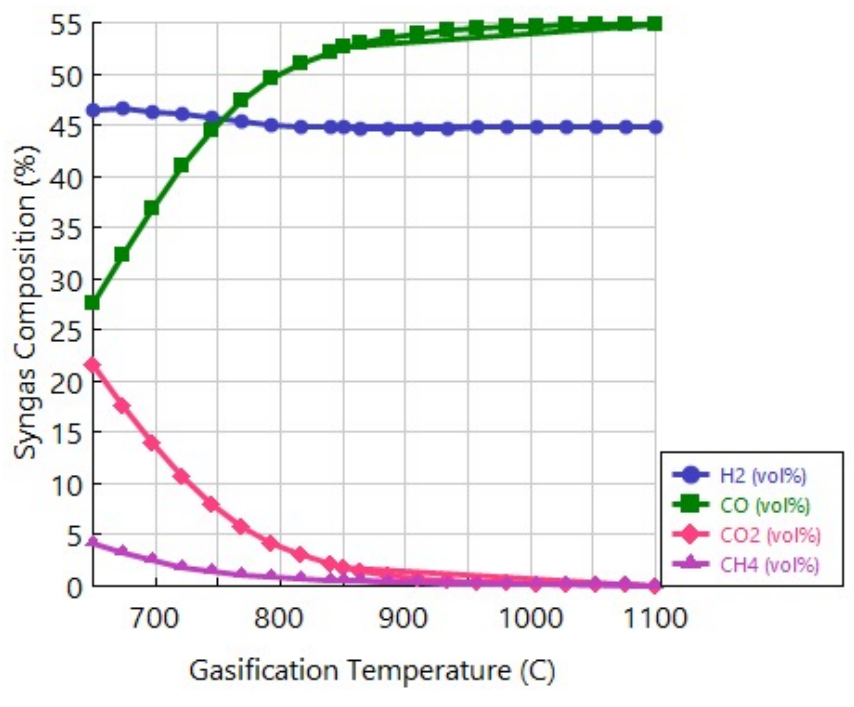

Fig. 2. Effect of Gasification Temperature on Syngas Composition.

\section{A. Effect of Gasification Temperature}

Fig. 2 shows that over the gasification temperature range from 650 to 1100 , the $H_{2}$ content decreased from $46.5 \%$ to $44.9 \%$. $C O$ increases significantly from $27.5 \%$ to $54.9 \%$ while both $\mathrm{CO}_{2}$ and $\mathrm{CH}_{4}$ decreased. $\mathrm{CO}_{2}$ decreased by $21.52 \%$ and $\mathrm{CH}_{4}$ almost disappears. The result is because the char gasification reaction and Boundouard reaction are endothermic reactions. Increasing temperature will move the equilibrium point forward, which encourages the consumption of char and $\mathrm{CO}_{2}$ to generate more $\mathrm{CO}$. Meanwhile, the water-gas shift reaction is exothermic reaction; increasing temperature will move the equilibrium point backward which has the same effect on the $\mathrm{CO}$ and $\mathrm{CO}_{2}$ as the Boundouard reaction. The $\mathrm{H}_{2}$ yield is dominated by both the char gasification reaction and waterature will move the equilibrium point forward in endothermic reaction resulting in the increase of $\mathrm{H}_{2}$ yield. But for water-gas shift reaction, the equilibrium point will move backward, which resulting in the decrease of $\mathrm{H}_{2}$ yield. Therefore the $\mathrm{H}_{2}$ content is almost unchanged.

The general trend of the LHV increases with the increase of the gasification temperature is illustrated in Fig. 3. This is because when the gasification temperature increases, the content of $C O$ increases while there is little change in other combustible gas content, which results in the increase of LHV, when the gasification temperature increases from $650^{\circ} \mathrm{C}$ to 
TABLE I

Basic Reactions in GaSification of CARbonaceous Materials [2]

\begin{tabular}{lcc}
\hline Reaction & Reaction Name & $\Delta H_{25 c}\left(\frac{\mathrm{Kj}}{\mathrm{mol}}\right)$ \\
\hline Biomass & $\begin{array}{c}\text { Pyrolysis } \\
\text { Pyrolysis reaction } \\
\text { Combustion }\end{array}$ & -111 \\
$\mathrm{C}+0.5 \mathrm{O}_{2} \rightarrow \mathrm{CO}$ & Partial combustion & -394 \\
$\mathrm{C}+\mathrm{O}_{2} \rightarrow \mathrm{CO}_{2}$ & Total combustion & -283 \\
$\mathrm{CO}+0.5 \mathrm{O}_{2} \rightarrow \mathrm{CO}_{2}$ & CO combustion & 172 \\
$\mathrm{C}+\mathrm{CO}_{2} \rightarrow 2 \mathrm{CO}$ & Reduction & 131 \\
$\mathrm{C}+\mathrm{H}_{2} \mathrm{O} \rightarrow \mathrm{H}_{2} \rightarrow \mathrm{CO}$ & Boudourd & -74.8 \\
$\mathrm{C}+2 \mathrm{H}_{2} \rightarrow \mathrm{CH}_{4}$ & Steam-Carbon & -41.2 \\
$\mathrm{CO}+\mathrm{H}_{2} \mathrm{O} \rightarrow \mathrm{H}_{2}+\mathrm{CO}_{2}$ & Hydrogasification & -206 \\
$\mathrm{CO}+3 \mathrm{H}_{2} \rightarrow \mathrm{CH}_{4}+\mathrm{H}_{2} \mathrm{O}$ & Water-gas shift & \\
\hline
\end{tabular}

TABLE II

Proximate AND Ultimate Analysis of SCB [5].

\begin{tabular}{cc}
\hline \multicolumn{2}{c}{ Proximate Analysis (w \%) } \\
\hline Moisture Content & 7.317 \\
Ash & 4.41 \\
Volatile Matter & 76.93 \\
Fixed Carbon & 11.33 \\
Ultimate Analysis (w \%) & \\
C & 46.95 \\
H & 6.06 \\
O & 46.78 \\
N & 0.13 \\
S & 0.08 \\
\hline
\end{tabular}

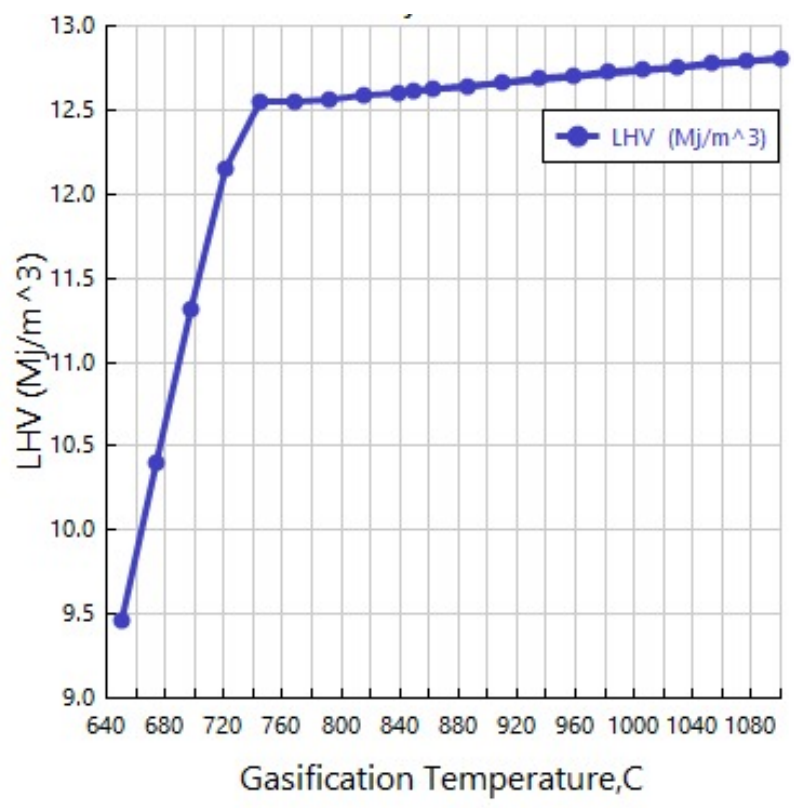

Fig. 3. Effect of Gasification Temperature on the LHV of Syngas.

$744^{\circ} \mathrm{C}$, the LHV of the syngas increased sharply from 9.45 to $12.55 \mathrm{Mj} / \mathrm{m}^{3}$. According to equation (2), CGE is dependent on different parameters of syngas yield, high heating value of fuel (HHV) and LHV of syngas, but it eventually depends on the amount of carbon monoxide, hydrogen and methane in the

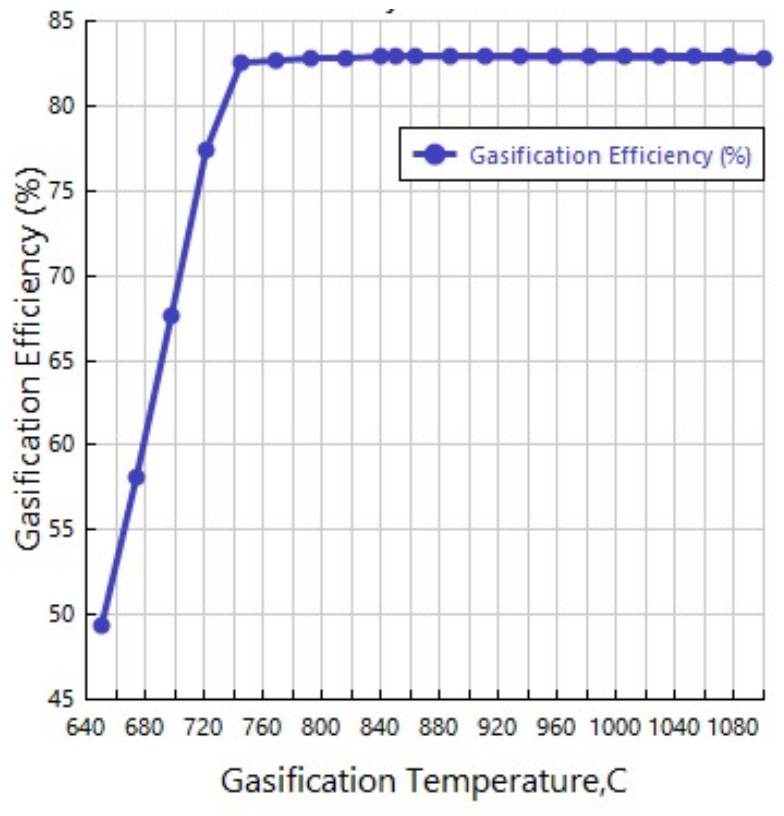

Fig. 4. Effect of Gasification Temperature on Gasification Efficiency.

product syngas. The effect of gasification temperature on gasification efficiency is illustrated on Fig. 4. When gasification temperature increases from $650^{\circ} \mathrm{C}$ to $745^{\circ} \mathrm{C}$, the gasification efficiency increased from $49.4 \%$ to $82.6 \%$. As the temperature increases from $750^{\circ} \mathrm{C}$ to $1100^{\circ} \mathrm{C}$ the efficiency almost remains stable.

\section{B. Effect of Steam to Biomass Ratio}

Fig. 5 shows the effect of the steam to biomass ratio on the syngas composition (vol. \% dry basis).As the steam to biomass ratio increases from 0.2 to $1, H_{2}$ Increased from $33.1 \%$ to $44.8 \%$. Both $\mathrm{CO}$ and $\mathrm{CO}_{2}$ Decreased. $\mathrm{CO}$ dropped from $63.6 \%$ to $52.6 \%$ and $\mathrm{CO}_{2}$ from $4.344 \%$ to $22.06 \%$. $\mathrm{CH}_{4}$ Content is very low. From a thermodynamic point of view, if other reactants are constant, increasing the steam mass flow rate means increasing the concentration of the reactants. This result in the equilibrium point moves forward and more products are generated. In char gasification reaction, steam 
DESCRIPTION OF THE BLOCKS USED IN THE MODELING.

\begin{tabular}{lll}
\hline Module Name & Block ID & Description \\
\hline R-Yield & DECOMP & $\begin{array}{l}\text { Used for the conversion of the non-conventional stream biomass into conventional components. A calculator } \\
\text { block was used to determine the productâÁts composition. } \\
\text { Does not require the knowledge of the reaction stoichiometry. It uses Gibbs free energy minimization with } \\
\text { phase splitting to calculate equilibrium. It also allows restricted equilibrium specifications for systems that do } \\
\text { not reach complete equilibrium. }\end{array}$ \\
RGIBBS & GASIFIER & $\begin{array}{l}\text { Descent thermal and change phase state of the (AFT-GASF) stream by cooling down temperature. } \\
\text { Used for separating of water and ash (OTHERS) from the AFT-GASF main stream, as a result of this separation } \\
\text { process the product gas, (SYNGAS) is obtained. }\end{array}$ \\
Flash2 & COND &
\end{tabular}

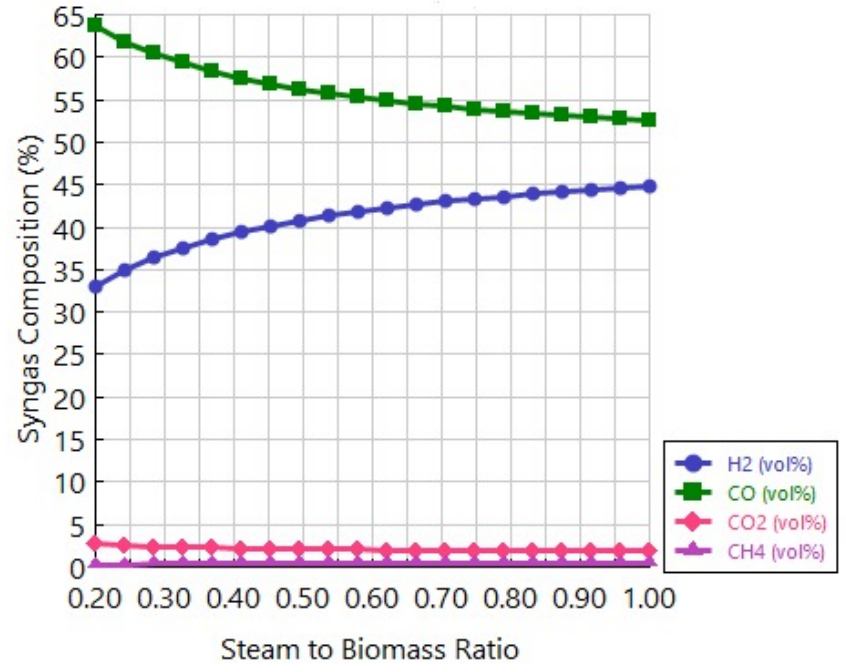

Fig. 5. Effect of SBR on Syngas Composition.

reforming reaction, and water-gas shift reaction, char, $C O$ and $\mathrm{CH}_{2}$ are consumed to generate more $\mathrm{H}_{2}$ and $\mathrm{CO}_{2}$. From this result, increasing steam to biomass ratio has a positive effect on obtaining high $H_{2}$ syngas, but the heat consumption for the generation of steam should also be considered as the endothermic behavior of steam carbon reaction.

The effect of steam to biomass ratio on the LHV of syngas is illustrated in Fig. 6. With the steam to biomass ratio increased from 0.2 to 1.0 , the LHV of the syngas decreased from 12.96 $\mathrm{Mj} / \mathrm{m} 3$ to $10.75 \mathrm{Mj} / \mathrm{m}^{3}$. By referring to Fig. 5, when the steam to biomass ratio increases, the $\mathrm{H}_{2}$ content increases while the $C O$ decreases significantly. Since the LHV of CO is $12.622 \mathrm{Mj} / \mathrm{m}^{3}$, (NREL data), which is higher than the LHV of $\mathrm{H}_{2} \quad 10.788 \mathrm{Mj} / \mathrm{m}^{3}$, (NREL data), the reduction of $\mathrm{CO}$ results in reducing the LHV of the syngas. Therefore the LHV of the syngas decreases with the increase of steam to biomass ratio. The effect of steam to biomass ratio on the gasification efficiency is illustrated on Fig. 7. When steam to biomass ratio increased from 0.2 to 0.289 , the gasification efficiency increased from $74.6 \%$ to $80.8 \%$ then it raised slightly to $81 \%$ upon the range of SBR from 0.333 to 1 .

\section{Effect of Air to Biomass Ratio}

Fig. 8 shows the effect of air to biomass ratio on the syngas composition (vol. \% dry basis). At low ABR, biomass reactions will approach to the pyrolysis, whereas at a high ABR

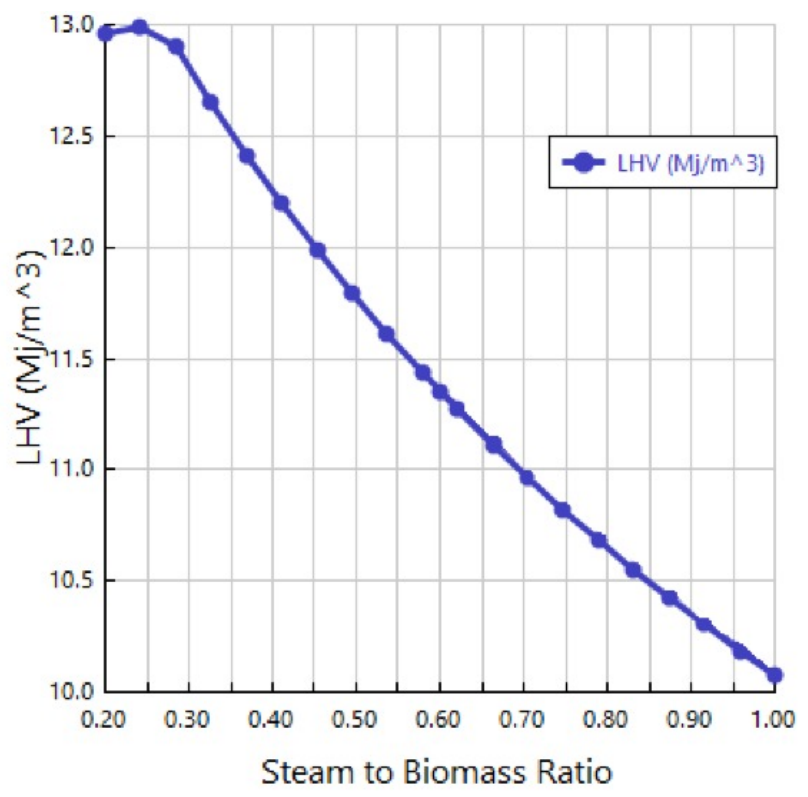

Fig. 6. Effect of SBR on the LHV of Syngas.

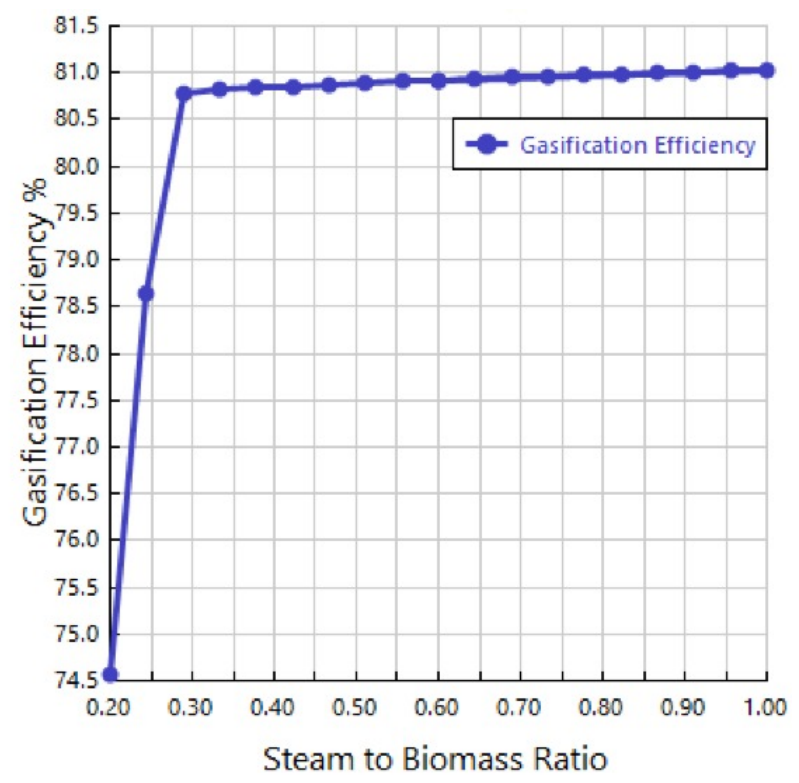

Fig. 7. Effect of SBR on Gasification Efficiency.

the excess amount of oxygen oxidizes the fuel completely and causes biomass combustion; then the production of syngas 


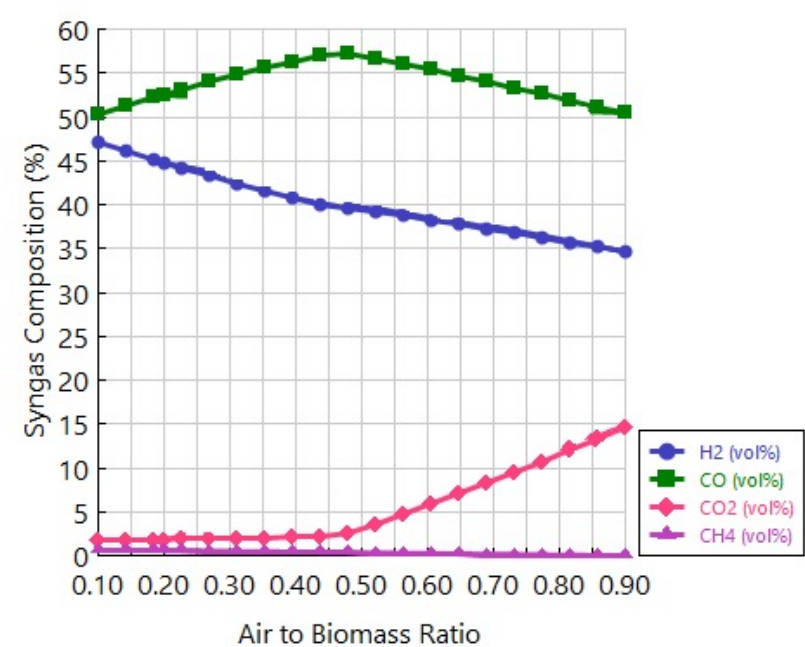

Fig. 8. Effect of ABR on Syngas Composition.

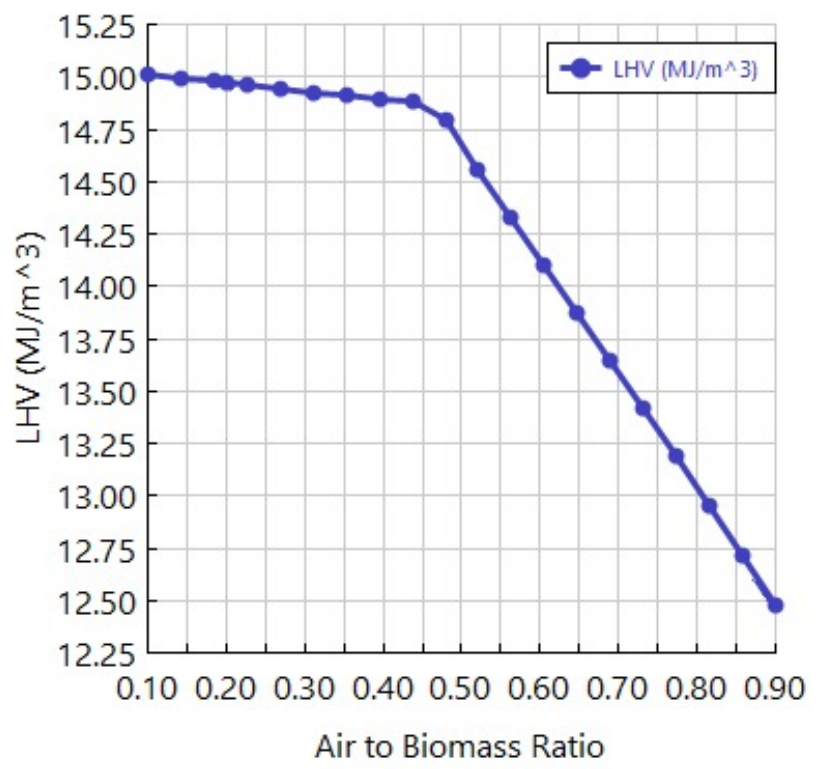

Fig. 9. Effect of ABR on the LHV of Syngas.

declines. Hence, it is important to find the appropriate range of ABR for biomass gasification that has been studied in this work. Higher air to biomass ratios lead to enhancement of combustion reactions so that $\mathrm{CO}_{2}$ content increases from $4.7 \%$ to $30.8 \%$ while the content of other $\mathrm{CO}$ was almost constant. Volume of $\mathrm{H}_{2}$ draws out from $45 \%$ to $26.5 \%$. $\mathrm{CH}_{4}$ decreases from $0.55 \%$ to $0.22 \%$.

The effect of air to biomass ratio on the LHV of the syngas is illustrated in Fig. 9. When the air to biomass ratio increased from 0.1 to 0.9 , the LHV of the syngas decreased from $15 \mathrm{Mj} / \mathrm{m} 3$ to $12.5 \mathrm{Mj} / \mathrm{m} 3$.This decreasing is obvious after $\mathrm{ABR}$ value 0.437 . By increasing $\mathrm{ABR}$, the production of carbon monoxide and hydrogen in syngas decrease due to complete combustion of fuel, so the heating value of the syngas decreased.

The effect of air to biomass ratio on gasification efficiency is illustrated on Fig. 10. When air to biomass ratio increased

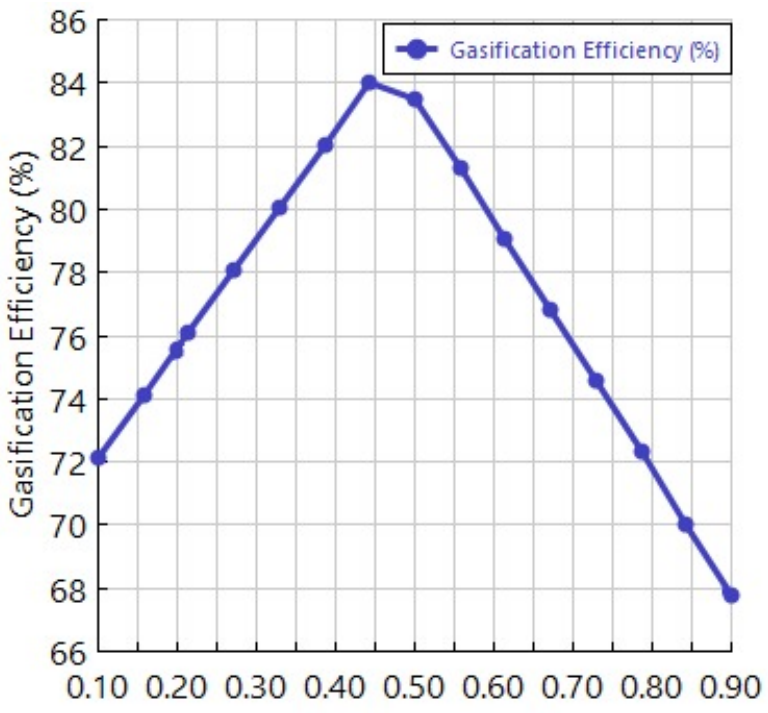

Air ti Biomass Ratio

Fig. 10. Effect of ABR on Gasification Efficiency.

from 0.1 to 0.9 , the gasification efficiency increased from $72 \%$ to $84 \%$.Maximum gasification efficiency $(84 \%)$ is obtained at ABR 0.443. Stemming from the reduction of LHV and gasification efficiency above the ABR value should be maintained lower than 0.443 .

\section{CONCLUSIONS}

Aspen Plus software was used, to develop a model for the gasification of sugar cane bagasse in a fluidized bed reactor, in order to simulate different streams and reactors were selected and combined. The equilibrium and steady state conditions were considered, but the tar formation and reaction kinetics were neglected. The gasifier is a minimization of Gibbs free energy model. Key operation parameters were gasification temperature, steam to biomass ratio and air to Biomass ratio were varied by implementing sensitivity analysis blocks. The effects of these parameters on the syngas composition, LHV of the syngas and the cold gasification efficiency were studied. Raising the gasification temperature increases the production of $\mathrm{CO}$ and $\mathrm{H}_{2}$ which leads to higher syngas yield, LHV and CGE. Increasing the SBR results in the increase of the hydrogen yield, consequently the proportion of hydrogen content in the syngas and CGE, while increasing of ABR had a negative effect on the LHV of the syngas and yield of $C O$ and $\mathrm{H}_{2}$ and CGE. The optimal values of syngas composition, LHV and CGE were located at gasification temperature range from $750 \ddot{E} \not ̌ C$ to $950 \ddot{E} Z ̌ C$, steam to biomass ratio around 0.5 to 0.8 and air to biomass ratio values equal to or below 0.4 . Since this simulation was based on the minimization of Gibbs free energy model, the simulation based on the kinetic model can be further studied, also more studies for gasification by optimizing operating condition using different biomass green waste feed-stocks will be good for comparison and investigation of better energy yield. More researches on identifying efficient pre-processing and utilization methods 
that can be applied to bagasse to make it a suitable feedstock for energy production in thermochemical conversion systems.

\section{ACKNOWLEDGMENT}

First of all, I want to offer this end over to our GOD Almighty who gave me the peace of my mind and good health, patience and energy to finish this research. I would like to express my special thanks of gratitude to my role model and teacher Professor Hamid M. Mustafa who passed away last year, before completing this thesis, for his able guidance and support, may God have mercy on him. My Grateful regards and gratitude is to my supervisor Professor Ibrahim $\mathrm{H}$. Mohamed for his kind help and cooperative response. Special thanks to my father Dr. Mutaz Mahmoud, Whose affection, love, encouragement and prays make me able to get such success.

\section{REFERENCES}

[1] https://www.netl.doe.gov/research/Coal/energysystems/gasification/ gasifipedia/intro-to-gasification, accessed: 2 April 2019,10:30 Am.

[2] M. C. Acar and Y. E. Böke+, "Simulation of biomass gasification process using aspen plus," Simulation, vol. 25, p. 27, 2018.

[3] W. Doherty, A. Reynolds, and D. Kennedy, "The effect of air preheating in a biomass $\mathrm{cfb}$ gasifier using aspen plus simulation," Biomass and bioenergy, vol. 33, no. 9, pp. 1158-1167, 2009.

[4] _ - "Aspen plus simulation of biomass gasification in a steam blown dual fluidised bed," 2013

[5] E. M. Edreis and H. Yao, "Kinetic thermal behaviour and evaluation of physical structure of sugar cane bagasse char during non-isothermal steam gasification," Journal of Materials Research and Technology, vol. 5, no. 4, pp. 317-326, 2016.

[6] S. Ferreira, E. Monteiro, P. Brito, and C. Vilarinho, "A holistic review on biomass gasification modified equilibrium models," Energies, vol. 12, no. 1, p. 160, 2019.

[7] J. Haydary, Chemical process design and simulation: Aspen Plus and Aspen Hysys applications. John Wiley \& Sons, 2019.

[8] - Chemical process design and simulation: Aspen Plus and Aspen Hysys applications. John Wiley \& Sons, 2019.

[9] T. L. Kelly-Yong, K. T. Lee, A. R. Mohamed, and S. Bhatia, "Potential of hydrogen from oil palm biomass as a source of renewable energy worldwide," Energy Policy, vol. 35, no. 11, pp. 5692-5701, 2007.

[10] R. Mikulandrić, D. Lončar, D. Böhning, and R. Böhme, "Biomass gasification process modelling approaches," in 8th Conference on Sustainable Development of Energy, Water and Environment SystemsSDEWES Conference, 2013, pp. 1-13.

[11] T. B. Reed, B. Levie, and M. S. Graboski, "Fundamentals, development and scaleup of the air-oxygen stratified downdraft gasifier," Solar Energy Research Inst., Golden, CO (USA), Tech. Rep., 1987.

[12] K. Sun, "Optimization of biomass gasification reactor using aspen plus," Master's thesis, Høgskolen i Telemark, 2015.

[13] A. Tech, "Aspen physical property system 11.1," Aspen Technology, Inc., Cambridge, MA, USA, 2001.

[14] K. Ziemi ski and M. Frc, "Methane fermentation process as anaerobic digestion of biomass: Transformations, stages and microorganisms," African Journal of Biotechnology, vol. 11, no. 18, pp. 4127-4139, 2012.

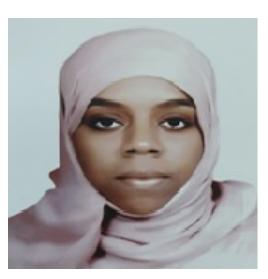

Mawa Mutaz Tagelsir is currently pursuing her $\mathrm{Ph} . \mathrm{D}$. degree from karary university, Khartoum, Sudan. She received her B.S. degree in 2014 from faculty of chemical engineering, Neelain University, Khartoum, Sudan. In 2016 she received her M.Sc. degree in petrochemical technologies from Karary University. Her current research interests include simulation processes of petrochemicals and Petroleum refining.

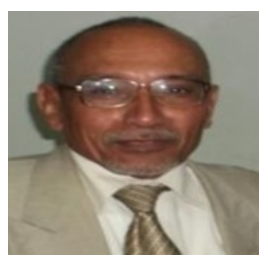

Hamid M. Mustafa was a professor of chemical engineering at several universities in Sudan and Kingdom of Saudi Arabia. He received his under graduate and post graduate degrees from Manchester University, United Kingdom. His research interests included petroleum refining, Mass transfer processes and translation of engineering science to Arabic.

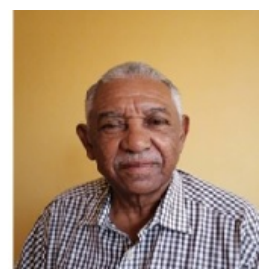

Ibrahim Hassan is a professor of chemical engineering at several universities in Sudan and Kingdom of Saudi Arabia. He received his under graduate and post graduate degrees in chemical engineering from Manchester University, United Kingdom. His current research interests include petroleum refining and Mass transfer processes. 